\title{
The Failure of Fast Ferry Catamaran Operations in New Zealand and Hawaii
}

\author{
Gui Lohmann ${ }^{1}$, Jakob Trischler ${ }^{2}$ \\ ${ }^{1}$ School of Tourism and Hospitality Management, Southern Cross University, Gold Coast, Australia \\ ${ }^{2}$ Southern Cross Business School, Southern Cross University, Gold Coast, Australia \\ Email: gui.lohmann@scu.edu.au
}

Received January 4, 2012; revised February 28, 2012; accepted March 14, 2012

\begin{abstract}
Fast ferry catamarans have been in use for several decades. They possess the advantage of overcoming one of the major deficiencies of water transportation: low speed. Although their operation has spread throughout different parts of the world, an overall analysis of the implementation and failures of this technology remains underdeveloped in the transport literature. This paper presents and compares two unsuccessful experiences of the use of fast ferry catamarans in New Zealand and Hawaii. Although both attempts possess major differences in terms of their contexts, particularly regarding competition, regulatory and environmental issues, some of the common lessons learned from both experiences can significantly contribute to a better understanding of this water transport technology and the challenges involved in its operation.
\end{abstract}

Keywords: Fast Ferry Catamaran Technology; Cook Strait Ferries; New Zealand; Hawaii Superferry

\section{Introduction}

Since the overall decline of long-distance passenger water transport in the 1960s, when wide body jets supplanted ships as a means of carrying travelers across the world, the development of fast ferries have been one of the most important factors to boost passenger water transport. Since their creation in Norway during the 1970s, resulting from the difficulties of land transport due to the specific topography of the west coast of this country [1], fast ferries have evolved into different shapes and sizes and are currently used for different purposes, including short-distance public transport in urban areas, medium-haul trips carrying a combination of passengers and freight transport, freight-only operation, military operation, patrolling, fire rescue and pollution control. The literature accounts for a number of ferry operations in different parts of the world, including Europe, Japan and New Zealand [2-4]. In addition, a number of references have addressed the technologies used by fast ferries, particularly the engineering of certain components and the structural designs that comprise these ships [e.g. 5-7].

This paper aims to contribute to the literature on transport technology by presenting two unsuccessful attempts to introduce interisland fast ferry catamaran technology in New Zealand and Hawaii. It uses mainly secondary data from written media to chronologically reconstruct the development and failure of these two cases. In the New Zealand case, the NZ Maritime Index was used, leading to the collection of information from industry reports. This paper also benefited from a larger research project addressing the two case studies, in which interviews with the then-existing ferry providers in New Zealand and Hawaii were conducted in 2005 and 2009, respectively. Although only a few interviews were conducted, they helped to provide a better understanding of the information obtained from secondary data. A discussion comparing both cases in terms of the major issues responsible for why both fast ferry experiences in the Pacific were unsuccessful is given. Although different in many respects, including competition, length of operation of the fast ferry technology and political and policy matters, these differences, as well as some similarities between the two cases, are worth understanding for the benefit of transport operators, as well as policy makers and transport planners. This is particularly useful in the case of Hawaii, as in many aspects the management issues of the fast ferry service in New Zealand have been previously presented in the literature $[8,9]$. Conclusions are then drawn.

\section{Fast Ferry Catamaran Technology}

Speed is becoming a major factor in the choice of transport in the modern world, and water transport has always 
been among the slowest forms of transport, with the average speed of conventional ferries ranging between 15 and 18 knots [10]. With the advent of high-speed crafts, water transport providers have had more options to compete with other modes of transport, particularly airlines, by providing faster and more expensive water transport alternatives than conventional ferries. During the 1980 s and 1990s, fast ferry transport has been one of the fastest-growing sectors within the maritime transport sector [11]. This is becoming particularly relevant in developed countries due to the growing phenomenon of "money rich-time poor" societies, which implies a high demand for quicker transportation modes [12]. Reaching speeds of up to 55 knots, fast ferries significantly reduce total travel times in comparison to conventional vessels [13].

Currently, there is a wide range of high-speed crafts, such as monohulls, small waterplane-area twin-hull (SWATH) wave-piercing catamarans, hovercrafts, surface-effect ships (SES) and hydrofoils [14]. Most of these vessels are constructed from aluminum and powered by high-speed diesel engines and waterjets. To address the increasing regulation concerning the environment, safety and comfort, fast ferry manufacturers have developed many different hull and engine designs to meet these requirements [15].

Bonafoux et al. [16] undertook a comparative study between three key hull forms, namely a monohull, a catamaran and a newly developed multihull version called a "pentamaran". To make the different vessel designs comparable, it was assumed that all vessels had the same payload capacity as well as the same fuel load and engine. The catamaran was rated best in "motion sickness incidence" (MSI) in beam seas. In other measurements, such as wave wash, heave response, slamming and head seas performance, the catamaran performance was rated as the weakest, whereas the pentamaran hull form showed very strong results [see also 6]. A further disadvantage of the catamaran is related to the bridging structures between the hulls, which are often considered the most serious problem associated with the safety of multihull vessels [17]. Another study, conducted by Inoue and Kamruzzaman [18], reported that the size and fineness of the bulb are significant factors in reducing the motion response and the relative wave height under the deck structure of multihull vessels.

Despite numerous criticisms and concerns, especially regarding the seakeeping performance in moderate to heavy seas, the catamaran hull form is still the preferable option among most fast ferry operators [19]. The main reason is the high level of passenger comfort, also stated as low MSI, at higher speeds due to the transverse stability of catamaran hull forms [20]. Further advantages, in comparison to the monohull, include the larger deck area and higher speed/fuel efficiency. In calm seas and at travel speeds over 35 knots, the power requirements for a catamaran are more than $30 \%$ lower than those for a monohull craft [16]. Hence, catamarans have dominated the fast ferry market, representing over $70 \%$ of all high-speed ferries and possessing a competitive speed range of up to 55 knots $[1,11]$.

Fast ferry catamarans are currently in operation in many parts of the world, with popular routes including the Cross Channel Ferries between the UK and mainland Europe, in Greece and those within Scandinavian countries. Nevertheless, fast ferry routes between England and France have encountered major problems, mostly of the financial or reliability nature. Outside Europe, some popular routes are operated in California and the east coast of the US, between Argentina and Uruguay, between Macau and the Hong Kong international airport, as well as in Japan. This paper covers two geographical areas in the Pacific that have only recently received attention in the ferry transport literature [4,21,22].

\section{The Fast Ferry Catamaran Experiences in New Zealand and Hawaii}

\subsection{Cook Strait Ferries, New Zealand}

The ferry operation across Cook Strait, between Wellington and Picton (see Figure 1), dates from August 1962, and for more than thirty years, the incumbent ferry company, The Interisland Line, only used conventional roll-on roll-off vessels. This changed at the end of 1994, when fast ferry technology was introduced, with a number of competitors challenging the incumbent company throughout the following decade. All of these competitors operated with only one vessel at a time, combining small-passenger-only ferries and large-passenger and vehicle catamarans (see details in Table 1). In addition to its conventional ferry operation, the incumbent company introduced The Lynx service, which, throughout its life span of nearly ten years, made use of different large-passenger and vehicle fast ferry catamaran vessels (Condor 10, Condor Vitesse, Incat 057 and Incat 046).

At the beginning of 1994, three possible competitors were planning to start a fast ferry service across Cook Strait. Only one, Sea Shuttles NZ Ltd. (hereafter referred to as Sea Shuttles), became a legitimate competitor. This coincided with the decision by The Interisland Line to introduce a fast ferry service with the vessel Condor 10 . Competition started during the month of December. The Condor 10 made her debut as scheduled on 21 December [23]. After ten frustrating days in dry-dock for repairs and several route familiarization trips later, Albayzin's first inaugural trip was shortly followed by other issues, including the fact that its timetable was too ambitious, despite warnings that it had allowed insufficient time for the turnaround at Wellington. In addition, after striking 


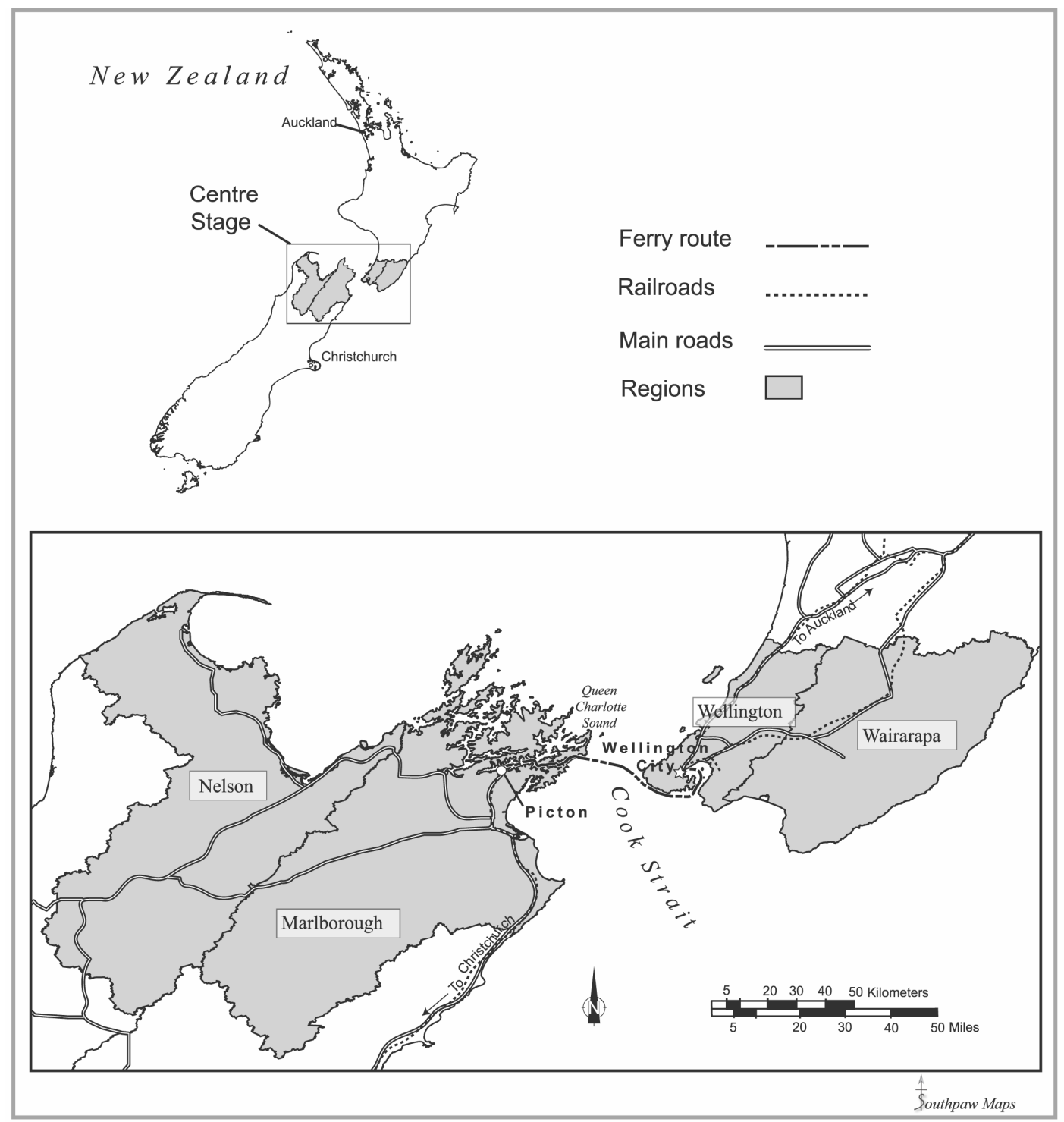

Figure 1. The cook strait ferry route.

Table 1. Details of the interisland line's fast ferry competitors.

\begin{tabular}{ll}
\hline Company (period of operation) & Characteristics of the vessel \\
\hline Sea Shuttles (Dec 1994 - Mar 1995) & Albayzin: 3.265 gross-tonnage, 450 passengers and 84 cars in up to 37 knots \\
North by South Ferries (Dec 1995 - May 1996) & StraitRunner: passenger only 31-meter monohull ferry \\
Sea Cat Ferries (Feb 1998 - May 1999) & Te Hukatai: $25 \mathrm{~m}$, 208-gross-tonnage, able to carry 150 passengers in up to 28 knots \\
Fast Cat Ferries Ltd (May 1999 - Nov 2000) & Incat 050: able to carry 775 passengers and 240 cars up to 38 knots \\
\hline
\end{tabular}

the wharf heavily at Picton while berthing on 29 December, it became evident that Albayzin's hard-chine hull shape lacked the necessary fendering and was very susceptible to wharf damage [24].

Meanwhile, by the beginning of January 1995, speed restrictions within Wellington Harbor had been placed on both fast ferries after concerns were expressed about the effect of their wakes on other ships [25]. The new restrictions added an extra 15 minutes to the usual 1.5-hour interisland crossing. In addition, protests were made by Tory Channel (see Figure 1) residents about the adverse effects of fast ferry wakes. Sea animals, such as paua and kina, were being tossed on the shore to die; rocks were being thrown onto beaches and erosion was eating away 
at banks and boat sheds.

On 4 January 1995, following an incident at Picton when Albayzin nearly grounded while berthing with three engines shut down, the Maritime Safety Authority cancelled Sea Shuttles' operating certificate, citing serious concerns about the ship's safety and seaworthiness [24]. The Picton incident was the latest in a run of steering problems experienced by the vessel, including two on 26 December 1994, when the ship made two involuntary 360-degree turns at high speed. Although the Albayzin was considered smoother and more luxurious than Condor 10 , the crew had struggled with engine and berthing difficulties. Albayzin's last trip was on 14 February 1995 [26].

In its second season (1995-6), The Lynx faced a new competitor, North by South Ferries, whose inaugural trip was on 19 December 1995. At the beginning of 1996, the Maritime Safety Authority decided to investigate North by South because it was operating the StraitRunner during heavy seas. Ferry sailings often proved to be unreliable because the StraitRunner's limited operating parameters prevented it from sailing in seas higher than 2.5 meters. In February, a drop in passenger numbers forced the company to revise its timetable and close its Wellington office [27]. In the first days of May, North by South went into receivership, ending its service across Cook Strait [28].

The Lynx's third summer season started on 13 December 1996 and ended on 2 April 1997. This was the first season in which it ran without a competitor. On 6 December 1997, Condor 10 arrived back in Wellington for The Lynx's fourth season of operation. As in previous years, the service ran from the beginning of December until Easter [29]. In February 1998, another operator, Cook Strait Sea Cat Ferries, started the first year-round, passenger-only, fast ferry service between Porirua and Picton. Due to her small size, Te Hukatai was barred from operating if the wave height exceeded three meters, and it was subject to speed restrictions. According to Pryce [30], she had problems a few days after her inaugural trip, mainly due to heavy rain, bad weather and propeller repairs, until the month of May. In spite of these issues, Te Hukatai became the first fast ferry to run during the winter season, with only two return trips.

The year 1999 brought some changes to the Cook Strait ferry scenario. For the first time, three fast ferries were in operation, when Fast Cat Ferries started operating the Incat 050 on 10 May. With the arrival of Top Cat, The Interisland Line announced that it would retain Condor 10 for a limited winter service, operating the vessel on weekends only [31]. By this time, there were three fast ferry vessels (Te Hukatai, Incat 050 and Condor 10) running during the low season in addition to the three conventional ferries. Altogether, the fast ferries offered more than 3000 seats daily across Cook Strait, for an average demand of about 400 passenger crossings a day. As a result, Sea Cat Ferries ceased operations and closed down service on 1 June 1999 [31].

In June 1999, however, Condor 10's owners devised a better deal and accepted a lease for the vessel, leaving Incat 050 as the only fast ferry over the winter, with two return trips daily. Consequently, Top Cat heralded the introduction of fast freight during wintertime and soon proved popular with freight operators and the travelling public alike.

In July 2000, the Marlborough District Council passed a bylaw halving the speed of fast ferries to 18 knots through the Sounds because of concerns that their wakes were damaging the environment and private property. As a result, fast ferries would cruise Cook Strait in two hours and fifteen minutes (half an hour longer than before), in comparison to the three-hour trip of a conventional ferry. The advantages of a fast ferry journey became less appealing, taking into account its more expensive fare. These new speed restrictions imposed on the fast ferries soon led to the end for Fast Cat Ferries [32].

During the years 2001-2002, The Interisland Line was, once again, the only ferry operator. However, at the beginning of 2003, Strait Shipping introduced a passenger and vehicle service named Bluebridge, using a conventional ferry called Santa Regina. The increase in competition from a more sustainable competitor operating a conventional ferry, as well as the fact that the fare charges were very similar to those of the conventional ferries, in spite of the higher costs associated with the operation of a fast ferry catamaran (see Table 2), brought The Lynx service to an end in April 2005. Between 2005 and the beginning of 2011, no other attempts were made to introduce a fast ferry across the Cook Strait, and the two operators retained mainly the same ships as those presented in Table 2, with the exception of The Lynx service, which was discontinued, and of a second conventional ferry, The Straitsman, added by Bluebridge in December 2010.

\subsection{The Short Life of the Hawaii Superferry}

In Hawaii, interisland ferry transport started much later than it did in New Zealand. It also had a much shorter lifespan. In August 2007, the Hawaii Superferry started passenger and vehicle transport between Honolulu, on the island of Oahu, to Kahului Harbor on Maui (see Figure 2). Superferry contracted Austal USA, which built the Alakai and, later, the Huakai, at a cost of US $\$ 80$ million per vessel. The Alakai was the only vessel to actually operate, as the company ceased operation in March 2009, before the Huakai vessel was delivered. These ships were hulled-hulled catamarans capable of trans- 
porting up to 866 passengers and 282 cars. In spite of the state investment of US \$46 million in harbor improvements to accommodate the Superferry operations, in a demonstration voyage to the island of Kauai, the Alakai was met with large protests at Nāwiliwili Harbor, where protestors expressed a number of concerns that can be divided into social, environmental, traffic, and legal is- sues. Table 3 provides a chronological summary of the development of Hawaii Superferry.

Social impacts revolved around the potential of drugs from Oahu entering the outer islands through the ferry and the migration of homeless people between islands. Outer island communities also expressed anxiety over the possibility that this new mode of transportation would

Table 2. Ferry services comparison-Spring 2003 and Summer 2004.

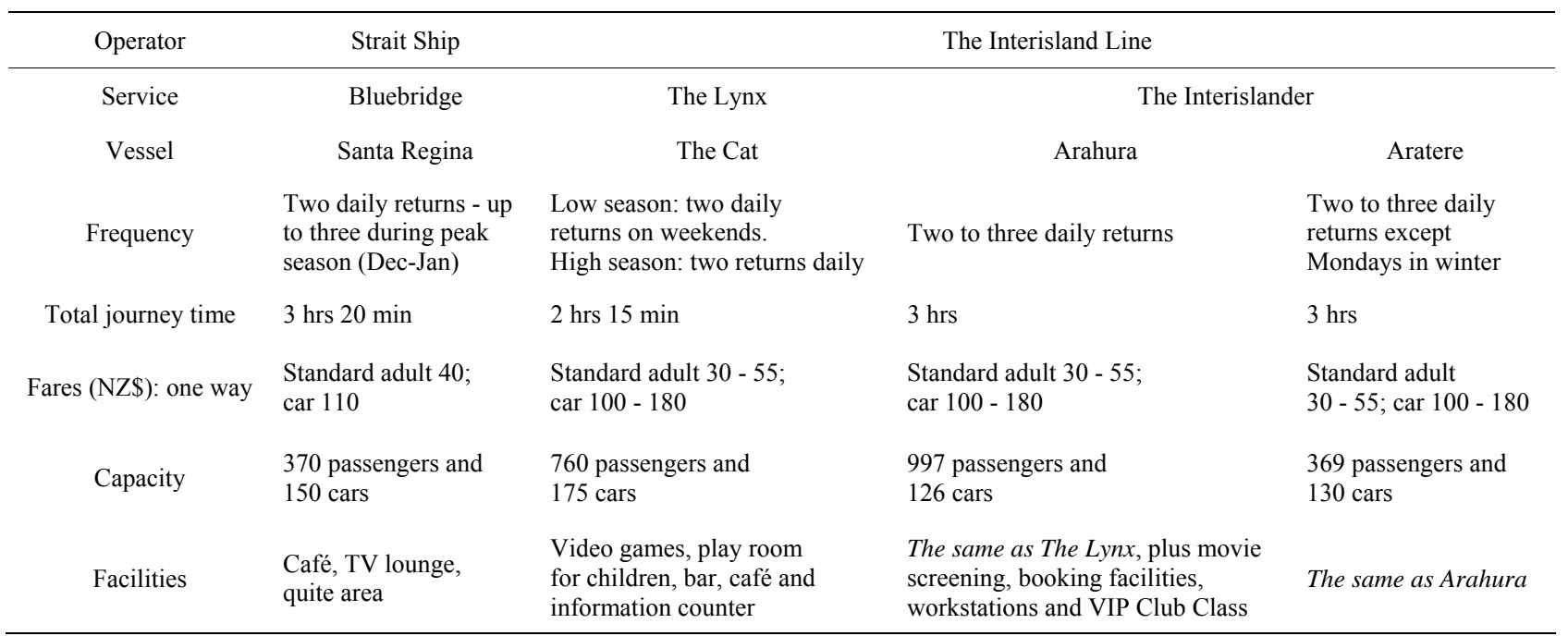

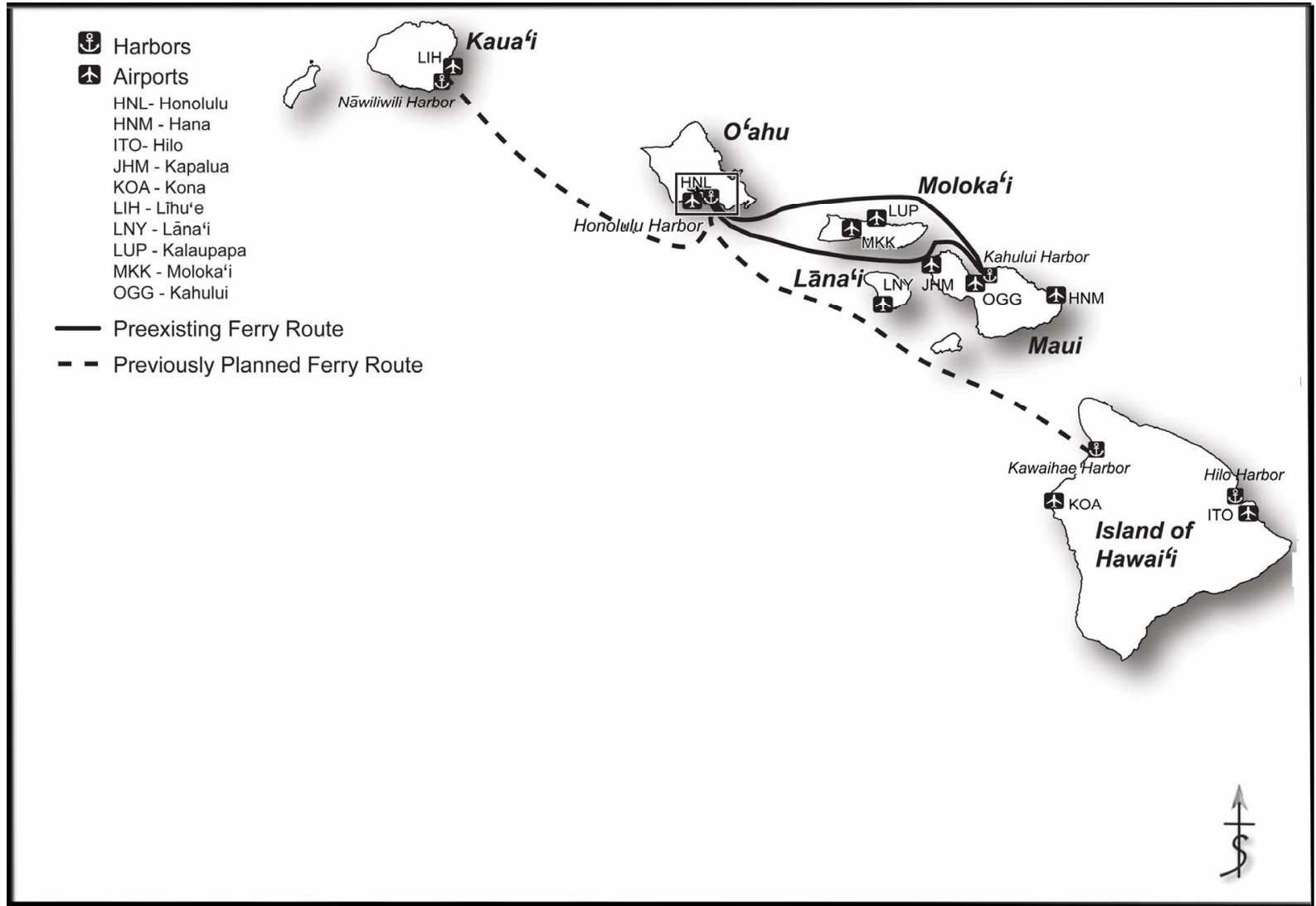

Figure 2. The superferry pre-existing and previously planned ferry routes in Hawaii. 
Table 3. The Superferry (SF) timeline (source: various editions of Honolulu Advertiser and Star-Bulletin newspapers).

\begin{tabular}{|c|c|}
\hline Date & Description of Event \\
\hline & Stage 1: Before Operation \\
\hline 13 Jun 03 & Three entrepreneurs start talking about developing Superferry (SF) in Hawaii. \\
\hline 23 Jan 04 & Formed partnership with Austal, two ships to be built. \\
\hline 9 Mar 04 & Pacific Whale Foundation protests introduction of SF. \\
\hline June 04 & First ship begins construction. \\
\hline 16 Nov 04 & Public hearings on SF. \\
\hline 30 Sep 05 & District judge dismissed environmental lawsuit against SF. \\
\hline \multirow[t]{2}{*}{23 Aug 07} & Supreme Court: DoT erred on Environment Impact Assessment (EIA). \\
\hline & Stage 2: During Operation \\
\hline 26 Aug 07 & Inaugural voyage. \\
\hline 27 Aug 07 & Restraining order on Kahului protests. \\
\hline 8 Oct 07 & Judge says cannot resume service until EIA done. \\
\hline 24 Oct 07 & Governor calls special session. \\
\hline 29 Oct 07 & Senate approves bill that allows ferry to operate while EIA is prepared. \\
\hline 14 Nov 07 & Injunction lifted banning ferry from sailing to Kahului. \\
\hline 14 Dec 07 & Restarted service to Maui. \\
\hline 15 Jan 08 & SF cancels second daily Maui trip. \\
\hline Dec 08 & Environmental groups go to court of appeals. \\
\hline 18 Mar 08 & Public meetings in Maui blast SF on EIA. \\
\hline 8 Jan 09 & The State DoT released a draft of the SF environmental report. No major concerns were identified. \\
\hline 21 Jan 09 & SF states it followed procedures in avoiding a whale after rumors of collision spread. \\
\hline 27 Feb 09 & SF cuts one-way fare prices to $\$ 39$. \\
\hline 16 Mar 09 & Hawaii Supreme Court says previous ruling unconstitutional, company lays off 236 employees. \\
\hline 19 Mar 09 & The last trip of the Hawaii SF. \\
\hline 30 Mar 09 & SF announces Alakai will head back to Austal for future employment. \\
\hline \multirow[t]{2}{*}{30 May 09} & SF files Chapter 11, declares bankruptcy. \\
\hline & Stage 3: After Operation \\
\hline 21 Aug 09 & Austal reports net profit fell by $82 \%$ as it was forced to write down SF's debt. \\
\hline 8 Sep 09 & Governor criticized the lack of political leadership in supporting SF. \\
\hline
\end{tabular}

increase the number of tourists to the outer island, straining the island's capacity and affecting the local ecosystem. The inclusion of vehicles on the ferry generated alarm over whether they would negatively affect traffic on the neighboring islands. In August 2007, a Maui judge ordered the Hawaii Department of Transportation (DoT) to implement traffic mitigation measures at Kahului Harbor to accommodate the traffic expected from ferry arrivals. However, after conducting a traffic impact study, the DoT maintained that the ferry would only add a marginal traffic increase in nearby streets [33].

The list of environmental issues was plentiful. By allowing the inclusion of vehicles on the ferry, there were concerns over the potential of transporting invasive species, such as coqui frogs and fire ants, to the outer islands. Although vehicles were inspected and washed prior to boarding the ferry, residents questioned the effectiveness of these preventive methods. The process of travelling 
between the islands also posed environmental risks, as the ferry may discharge ballast water into the ocean, potentially releasing many kinds of bacteria, plants, and other life that could be harmful to the local ecosystem. In addition, many of the proposed routes would traverse through areas containing humpback whale habitats, with concerns that the fast-moving ferries with sharp hulls could threaten the whales.

These environmental concerns led to a number of legal issues that plagued Superferry operations. In August 2007, the Hawaii Supreme Court stated that an environmental impact assessment would be required on statefunded harbor improvements, overturning the Maui Circuit Court's decision in 2005. Despite this, the ferry proceeded to travel to Nāwiliwili ahead of schedule. Continuing protests in Kauai led to the suspension of service to Nāwiliwili Harbor. In October 2007, the Maui Circuit Court demanded that the Superferry wait for an environmental impact assessment (EIA) to be completed before resuming service. However, after a meeting between the Governor and the Hawaii State Senate, Superferry was later allowed to resume service until the completion of the assessment [34]. By March 2009, the Hawaii State Supreme court found Superferry operations prior to the completion of the environmental impact assessment to be unconstitutional [35]. Following this announcement, Superferry terminated its work force and, by May, declared bankruptcy.

\section{Major Explanations for the Failures}

\subsection{Environmental Issues}

With the growing market and operation of high-speed vessels around the globe, environmental concerns are rising, especially in regards to wave wash and emissions due to significantly high fuel consumption [36]. The massive growth in exhaust emissions per passenger-mile and the great increase in external noise and waves generated by large high-speed ships are the major concerns of environmental studies [37-39]. Additionally, environmental impact studies on fast ferries have found that, whereas hull shape have little effect on resistance or wash, water depth [40] and the displacement/length ratio have a significant effect. The displacement/length ratio expresses the weight of a boat relative to its waterline length and hence enables a comparison between all kinds of vessels regardless of their size [41]. Particularly fast ferries show a high ratio of propulsion power to vessel displacement as it is a precondition for reaching high speeds. This, together with near-critical and supercritical speeds, leads to high loads on the coastal environment [39]. This has been confirmed in a series of studies conducted at Tallinn Bay, Estonia [37,39,42-44].

Thus, it comes as no surprise that, in New Zealand, the fast ferry environmental issues started just after the ferries began operation before Christmas 1994, with residents in Tory Channel noting that the wash produced by Condor 10 and Albayzin was substantially more powerful than the wash created by conventional ferries [45-47]. They became aware of numerous changes and effects along the Tory Channel shorelines, i.e., substantial erosion, the stranding and destruction of marine and bird life, the washing up of large boulders onto the shore, the disturbance of ancient burial grounds, potential damage to moored boats and structures such as boat sheds and ramps, and danger to individuals, particularly small children [48]. Soon, some residents formed a local organization called Save the Sounds - Stop the Wash (STS) that applied for an interim enforcement order [49]. The applications of STS, the Te Atiawa Trust and the Minister of Conservation were heard together before the Planning Tribunal in March and April 1995 [48]. In early May, the judge decided not to make an enforcement order restricting the operation of the fast ferries. The Tribunal was unable to determine whether the effects were of a sufficiently serious nature to merit a cessation order. Moreover, ferry service was considered of national importance and should not have been the subject of a cessation order on the basis of inconclusive and subjective evidence [50]. Finally, although the impact of the wash along the shore was found to have been severe enough to alter the equilibrium of the ecosystem, a new "ecological equilibrium" would be established [48,51]. It was decided, however, that the area would be monitored by scientists during the winter when fast ferries were not running to compare data with the next summer season $[52,53]$. On the other side of the strait, however, speed restrictions within Wellington Harbor had been placed on fast ferries. According to Bell [25], they had to stop at the first leading light at Ward Island to allow the pressure wave of their wakes to dissipate before continuing their journeys.

In the case of New Zealand, environmental complaints tended to surface each time that there was a change in ferry operation, either through the introduction of a new ship or a change in the sailing patterns. In 1986, for example, the Marlborough Sounds Maritime Park Board was concerned about the problem of erosion caused by ferry wash. On this occasion, it was claimed that the ferries were continuing to travel at up to 21 knots in the Sounds and that their wash had undermined a lighthouse in the area [54]. In January 2000, the issue of the fast ferry wash was raised again. By this time, seven conventional and fast ferries, Aratere, Arahura, Arahanga, Condor Vitesse, Incat 050, Suilven and Straitsman", made a total of up to eighteen sailings daily from Picton during the summer months [55]. For this reason, in July 2000, the Marlborough District Council decided to pass a

\footnotetext{
${ }^{1}$ The last two were operating as freight ferries
} 
bylaw restricting the speed of fast ferries from 35 to 18 knots in the Sounds [56,57]. Hence, the fast ferries' trip time increased from one hour and forty-five minutes to two hours and fifteen minutes. Moreover, the frequency of their services changed from three to two round trips per day.

In Hawaii, the discussion of environmental impacts, among other types of negative influences caused by the ferries, was of a broader nature and went beyond simply the impact of the ferry wash. It involved other issues that included concern over invasive species, particularly because of the interisland transport of vehicles by ferry, and marine life endangerment, as the ferry route passed through the Humpback Whale Marine Sanctuary. In part, some of these concerns can be attributed to the fact that the Superferry represented not only the introduction of fast ferry catamaran technology in Hawaii but also the beginning of ferry operation, particularly in terms of transporting vehicles between islands. In New Zealand, this was not a problem, as ferries had been in operation since the 1960s. In Hawaii, issues related to the fast ferry technology per se were mostly associated with threats to whales and their reproductive environment.

In the case of the Superferry, environmental impacts were the centre of the juridical discussion, and government battles involving the state executive government, the state legislature and the state Supreme Court ensued regarding the need for an environmental impact assessment to be performed before the Superferry could operate. The whole issue began earlier in 2004/5, when the federal DoT approved a loan guarantee for the Superferry to build its two vessels only if Hawaii State provided a blanket clearance without any environmental impact studies. The Hawaii State legislature then unanimously passed a resolution exempting the Superferry from bureaucratic obstacles. Later, this proved to be unconstitutional.

\subsection{Competition}

In terms of competition, the Interisland Line has always had a competitive advantage over newcomers [58]. First, it has had a long association with the ferry service- over forty years. Second, the company also has an equally long-established network of booking offices and contacts in New Zealand and abroad. A new operator starting from scratch would find it difficult to build up such an easily accessible nationwide booking service and would certainly not have The Interisland Line's deep knowledge of what the market wants. Third, it can offer an unrivalled frequency of service through its various services and vessels. A rival firm starting off with just one ship does not have that advantage.

In addition to these matters, most of The Interisland
Line's fast ferry competitors had issues with their vessels, either because of lack of experience in operating them or a lack of understanding of the challenges of these operations across the Cook Strait (e.g., Sea Shuttles with the Albayzin), or because they were operating small ferries that were restricted from operating during high seas, as in the cases of North by South Ferries and Sea Cat Ferries. The latter struggled to cope with two large competitors, The Interisland Line and Fast Cat Ferries, operating simultaneously during wintertime. Among The Interisland Line's previous competitors, however, Strait Shipping was not only the first to have a more experienced background knowledge of the Cook Strait, as it had operated freight ships for several years, but was also the first to put a conventional ferry, rather than a fast ferry catamaran, into service.

According to an interview with a former SuperFerry executive for this research, although the Superferry did not have a direct competitor in Hawaii, it had to deal with the intense lobbying that the traditional freight shipping companies, such as Matson Navigation, Horizon Lines and Young Brothers, put forth to financially support the "environmentally conscious". The Superferry provided a reliable, fast and convenient way for small and medium enterprises, particularly those working in food production, to transport their goods between islands by simply loading their vans and taking them on-board the ferries.

\subsection{External Stakeholders and Government Interference}

In New Zealand and Hawaii, fast-ferry operators were subjected to a series of external stakeholders and government agencies, which ultimately shaped their final outcome. Generally, these organizations can be grouped into two main groups:

- Government agencies: In New Zealand, these included the Maritime Safety Authority, the Marlborough District Council and the Minister of Conservation. In Hawaii, they included the State and Federal Department of Transportation, the State Governor, the State Supreme Court and the State Legislature;

- Residents and organized groups of the civil society: In New Zealand, they included the residents in Tory Channel represented by the Save the Sounds-Stop the Wash group and the Te Atiawa Trust, one of the seven Maori tribes. In Hawaii, they included three major groups located in Maui: the Sierra Club, Maui Tomorrow and the Kahului Harbor Coalition.

In both places, residents and organized groups, usually located at the less-developed, environmentally more vulnerable, end of the ferry route, had a major role in protesting against the impacts caused by the fast ferries 
or taking legal actions against its operation. In fact, in Hawaii, protests were already made even before the beginning of the Superferry operation (see Table 3). The major difference between the two places occurred at the government level. In New Zealand, government action was taken through a step-by-step process, with the environmental impact assessment conducted in the Marlborough Sounds while the ferries were in operation. It took almost six years from the introduction of the fast ferry catamaran technology for a speed restriction to be implemented in the Marlborough Sounds. In Hawaii, the political influence and support for the ferry were very evident, up to a point where the State Supreme Court considered some of the decisions unconstitutional. Without going into the political reasons of why this happened, it was very clear that the State Governor personally supported the ferry operation. Among other things, she made the State DoT invest in harbor improvement while bargaining with the legislature to approve a bill exempting the Hawaii Superferry from requiring an environmental impact assessment. At the request of three community groups from Maui, the State Supreme Court found the situation unconstitutional, leading to the dismissal of the ferry company.

\section{Conclusions}

Despite the strong growth of fast ferry transport technology during the 1990s and 2000s, examples of failed transport ventures using this technology can be observed in different parts of the world, such as British Columbia (Canada), the English Channel, Hawaii and New Zealand; the latter two are presented in this paper. Unfortunately, the literature addressing these failures is very scarce. Some of the issues associated with the two areas presented in this paper include environmental and safety regulations, high acquisition and operating costs and strong competition driving operators into bankruptcy or forcing them to cease their operations. These experiences provide some valuable lessons that have not been previously discussed in the academic literature.

First, it is appropriate to discuss the choice of technology used in the presented case studies. In New Zealand, several of The Interisland Line competitors struggled with the novelty of operating a new technology without previous experience across the Cook Strait. Sea Shuttles, for example, had several issues with the Albayzin until the Maritime Safety Authority cancelled its certificate. North by South Ferries, on the other hand, had major issues dealing with a much smaller vessel due to its susceptibility to cancellations during heavy seas.

Second, while environmental issues were the common ground for the failure of fast ferry catamaran operation, the processes were very different in the two areas.
In New Zealand, regulatory agencies acted over a period of six years until speed restrictions were in operation on both sides of the ferry route. In Hawaii, the juridical battle was not over the terms of the conditions for the Superferry to operate but over the need to conduct an EIA before it could operate. In the end, some argued over why an EIA was not conducted if this was all the Superferry needed to operate. The usual response was, "Why fund one if it was not originally required?" In addition, the start-up company argued with the Governor that the need to undertake an EIA would delay the project by nine months and would divert investors to other opportunities. The introduction of a bill exempting the Superferry from an EIA created a major juridical precedent against the US Constitution, as the bill was seen as favoring one particular company. The argument imposed by Superferry supporters was in terms of why a new ferry operator would be required to conduct an EIA if the existing shipping lines and cruise lines never had to. The fragile juridical and executive government relationship in Hawaii proved to play a critical role in the failure of the Superferry.

Third, although much more evident in the case of New Zealand, competition played a major role in the failure of the various fast ferry competitors, as the incumbent, The Interisland Line, had a well-established brand and booking network on top of decades of experience operating across the Cook Strait route. The only competitor that has survived so far, Bluebridge, has not made use of the fast ferry technology. The Hawaii Superferry did not have direct competition, but maritime freight shipping companies lobbied against it, particularly supporting organized groups of local residents to protest against the Superferry and take legal action.

Finally, the dismissal of fast ferry operators had implications for both the tourism and freight sectors. In New Zealand, when the fast ferries were in operation without any speed restrictions across the Tory Channel, day trips out of Wellington constituted an important market, particularly when packages were put in place for visitors to explore the vineyards in the Marlborough region. An alternative route linking Wellington to Clifford Bay was, for many years, considered a viable solution for creating a more direct route to the South Island, but the project was never implemented because it required huge investments to develop a ferry port in Clifford Bay, as well as the fact that the rough sea of the Cook Strait could make the ferry trip less comfortable and increase cancellations. In Hawaii, the Superferry provided a different experience for tourists by giving the opportunity to sail and sightsee on the islands, which is usually not possible with interisland flights, and for tourists to take vehicles on-board the ferries. 


\section{Acknowledgements}

The authors are grateful for the useful and detailed comments provided by the two anonymous referees.

\section{REFERENCES}

[1] N. Gee, "Future Design Trends in High Speed Vessels," Nigel Gee and Associates Ltd., Vancouver, 1999.

[2] G. Dunlop, "The European Ferry Industry-Challenges and Changes," International Journal of Transport Management, Vol. 1, No. 2, 2002, pp. 115-116. doi:10.1016/S1471-4051(02)00005-8

[3] M. Graham and V. Russell, "Inverclyde Ferry Services: A Passenger Segmentation Analysis," Journal of Vacation Marketing, Vol. 7, No. 3, 2001, pp. 221-233. doi:10.1177/135676670100700303

[4] G. Lohmann and D. G. Pearce, "Conceptualizing and Operationalizing Nodal Tourism Functions," Journal of Transport Geography, Vol. 18, No. 2, 2010, pp. 266-275. doi:10.1016/j.jtrangeo.2009.05.003

[5] A. J. Haywood, A. J. Duncan, K. P. Klaka and J. Bennett, "The Development of a Ride Control System for Fast Ferries," Control Engineering Practice, Vol. 3, No. 5, 1995, pp. 695-702. doi:10.1016/0967-0661(95)00046-W

[6] G. A. Thomas, M. R. Davis, D. S. Holloway, N. L. Watson and T. J. Roberts, "Slamming Response of a Large High-Speed Wave-Piercer Catamaran," Marine Technology and SNAME News, Vol. 40, No. 2, 2003, pp. 126-140.

[7] T. Soomere, "Nonlinear Components of Ship Wake Waves," Applied Mechanics Reviews, Vol. 60, No. 3, 2007, pp. 120-138. doi:10.1115/1.2730847

[8] K. Parnell, S. McDonald and A. Burke, "Shoreline Effects of Vessel Wakes, Marlborough Sounds, New Zealand," Journal of Coastal Research, Vol. 50, 2007, pp. 502-506.

[9] K. E. Parnell and H. Kofoed-Hansen, "Wakes from Large High-Speed Ferries in Confined Coastal Waters: Management Approaches with Examples from New Zealand and Denmark," Coastal Management, Vol. 29, No. 3, 2001, pp. 217-237. doi:10.1080/08920750152102044

[10] T. Karayannis, A. Papanikolaou and A. F. Molland, "The Introduction of High-Speed Ferries into the Eastern Mediterranean," International Congress of International Maritime Association 2000, Ischia, 2-6 April 2000, pp. 1-11.

[11] D. B. McCafferty and K. P. McSweeney, "Comfort: Passengers, Crews and Fast Ferries," American Bureau of Shipping, New Orleans, 2001.

[12] L. Dwyer, D. Edwards, N. Mistilis, C. Roman and N. Scott, "Destination and Enterprise Management for a Tourism Future," Tourism Management, Vol. 30, No. 1, 2009, pp. 63-74. doi:10.1016/j.tourman.2008.04.002

[13] Hellenic Seaways, "Financial Results for the 9 Month Period to September 2007," 2007. http://www.hellenicseaways.gr/index.asp?a id=242\&new s_id $=172$

[14] J. Wang and S. McOwan, "Fast Passenger Ferries and Their Future," Maritime Policy and Management, Vol. 27,
No. 3, 2000, pp. 231-251. doi:10.1080/030888300411086

[15] M. Wickham, "Entrepreneurship and the Management of Innovation in the Global Marketplace: The Incat Story," The Management Case Study Journal, Vol. 5, No. 2, 2005, pp. 83-93.

[16] J. Bonafoux, E. Dudson and D. Sherwood, “An Evaluation of the Effect of Hull Form Choice on the Operability of Fast Ferries," Nigel Gee and Associates Ltd., Southampton, 2001.

[17] G. Bulian, A. Francescutto and I. Zotti, "Stability and Roll Motion of Fast Multihull Vessels in Beam Waves," Ships and Offshore Structures, Vol. 3, No. 3, 2008, pp. 215-228. doi:10.1080/17445300801990913

[18] Y. Inoue and M. Kamruzzaman, "Analysis of Hydrodynamic Characteristics for Arbitrary Multihull Ships Advancing in Waves," Journal of Marine Science and Technology, Vol. 13, No. 3, 2008, pp. 231-243. doi:10.1007/s00773-008-0001-X

[19] H. Moraes, J. Vasconcellos and P. Almeida, "Multiple Criteria Optimization Applied to High Speed Catamaran Preliminary Design," Ocean Engineering, Vol. 34, No. 1, 2007, pp. 133-147. doi:10.1016/j.oceaneng.2005.12.009

[20] C. C. Fang and H. S. Chan, "An Investigation on the Vertical Motion Sickness Characteristics of a High-Speed Catamaran Ferry," Ocean Engineering, Vol. 34, No. 1415, 2007, pp. 1909-1917. doi:10.1016/j.oceaneng.2007.04.001

[21] G. Lohmann and D. N. Nguyen, "A Holistic Approach to Sustainable Tourism Transportation in Hawaii," In: J. Carlsen and R. Butler, Eds., Island Tourism Development: Journeys toward Sustainability, CABI, Wallingford, 2011, pp. 197-214.

[22] G. Lohmann and D. G. Pearce, "Tourism and Transport Relationships: The Suppliers' Perspective in Gateway Destinations in New Zealand," Asia Pacific Journal of Tourism Research, Vol. 17, No. 1, 2012, pp. 14-29. doi:10.1080/10941665.2011.613211

[23] A. Finnegan, "Queasy First Trip for Ferry," The Evening Post, 21 December 1994, p. 1.

[24] S. Berry, "Fast Ferries on Cook Strait-The First Season Reviewed," The Transportant, 1995, pp. 6-10.

[25] C. Bell, "Hundreds Hit by Holdups," The Dominion, 4 January 1995, pp. 1-3.

[26] C. Bell, "Speeding across the Strait," The Dominion, 20 April 1995, pp. 4.

[27] A. Finnegan, "Ferry Collapse Threatens Other," The Evening Post, 2 May 1996, p. 1.

[28] A. Shelton, "Strait Runner Firm in Receivership," The Dominion, 2 May 1996, p. 1.

[29] M. Pryce, "Nautical News," New Zealand Marine News, 1997, pp. 191-222.

[30] M. Pryce, "Nautical News," New Zealand Marine News, 1998, pp. 24-58.

[31] M. Pryce, "Nautical News," New Zealand Marine News, 1999, pp. 78-102.

[32] J. O'Connor, "Cat Fight," The Evening Post, 28 October 2000, p. 28. 
[33] C. Wilson, "Superferry Still under Maui Traffic Order," Advertiser Neighbor Island Edition, 9 November 2007.

[34] Pacific Business News, "Lingle Signs Superferry Bill," Pacific Business News, 5 November 2007.

[35] C. Blair, "Hawaii Supreme Court Rules Superferry Law Unconstitutional," Pacific Business News, 16 March 2009.

[36] D. Kurennoy, I. Didenkulova and T. Soomere, "Cresttrough Asymmetry of Waves Generated by High-Speed Ferries," Estonian Journal of Engineering, Vol. 15, No. 3, 2009, pp. 182-195. doi:10.3176/eng.2009.3.03

[37] T. Soomere, J. Elken, J. Kask, S. Keevallik, T. Kouts, J. Metsaveer, et al., "Fast Ferries as a New Key Forcing Factor in Tallinn Bay," Proceedings of the Estonian Academy of Sciences, Engineering, Vol. 9, No. 3, 2003, pp. 220-242.

[38] T. Soomere and J. Kask, "A Specific Impact of Waves of Fast Ferries on Sediment Transport Processes in Tallinn Bay," Proceedings of the Estonian Academy of Sciences, Biology, Ecology, Vol. 52, No. 3, 2003, pp. 319-331.

[39] T. Soomere, "Fast Ferry Traffic as a Qualitatively New Forcing Factor of Environmental Processes in Non-Tidal sea Areas: A Case Study in Tallinn Bay, Baltic Sea," Environmental Fluid Mechanics, Vol. 5, No. 4, 2005, pp. 293-323. doi:10.1007/s10652-005-5226-1

[40] A. Hüsig, T. Linke and C. Zimmermann, "Effects from Supercritical Ship Operation on Inland Canals," Journal of Waterway, Port, Coastal, and Ocean Engineering, Vol. 126, No. 3, 2000, pp. 130-135. doi:10.1061/(ASCE)0733-950X(2000)126:3(130)

[41] I. W. Dand, T. A. Dinham-Peren and L. King, "Hydrodynamic Aspects of a Fast Catamaran Operating in Shallow Water," BMT SeaTech Ltd., London, 1999.

[42] T. Torsvik, I. Didenkulova, T. Soomere and K. Parnell, "Variability in Spatial Patterns of Long Nonlinear Waves from Fast Ferries in Tallinn Bay," Nonlinear Processes in Geophysics, Vol. 16, No. 2, 2009, pp. 351-363. doi:10.5194/npg-16-351-2009

[43] T. Soomere, R. Poeder, K. Rannat and A. Kask, "Profiles of Waves from High-Speed Ferries in the Coastal Area of Tallinn Bay," Proceedings of the Estonian Academy of Sciences, Engineering, Vol. 11, No. 3, 2005, pp. 245-260.
[44] T. Torsvik and T. Soomere, "Simulation of Patterns of Wakes from High-Speed Ferries in Tallinn Bay," Estonian Journal of Engineering, Vol. 14, No. 3, 2008, pp. 232-254. doi:10.3176/eng.2008.3.04

[45] C. Bell, "Trouble in Fast Ferries' Wake," The Dominion, 29 December 1994, p. 1.

[46] C. Bell, "Sounds Residents May Take Action over Ferries," The Dominion, 5 January 1995, p. 3.

[47] R. Croad and K. Parnell, "Proposed Controls on Shipping Activity in the Marlborough Sounds: A Review under S. 32 of the Resource Management Act," Opus International Consultants Ltd and Auckland UniServices Ltd, Marlborough, 2002.

[48] B. Pardy, "Fast Ferries: New Equilibrium Versus Ecological Sustainability," New Zealand Law Journal, Vol. 6, 1995, pp. 202-204.

[49] A. Taylor, "All Agree on Damage, Says Sounds Group," The Evening Post, 13 February 1995, p. 3.

[50] P. Milne and J. Tiller, "Making Waves: The Fast Ferries Decision," Resource Management Bulletin, Vol. 11, 1995, pp. 146-148.

[51] A. Taylor, "Ferry Decision 'Backward Step'-Law Lecturer," The Evening Post, 1 April 1995, p. 8.

[52] A. Shelton, "Faster Ferries' Teething Problems," The Dominion, 21 December 1995, p. 13.

[53] A. Taylor, "Lynx Wake Tests Could Avoid Speed Restriction," The Evening Post, 29 November 1995, p. 1.

[54] Rails, "New Ferries, New Terminals_-Possible Futures for NZ Rail's Interisland Line," Rails, August 1995, pp. 4-9.

[55] M. Pryce, "Nautical News," New Zealand Marine News, 2000, pp. 186-205.

[56] M. Pryce, "Nautical News," New Zealand Marine News, 2000, pp. 27-50.

[57] Marlborough District Council, "Use of Large, High Speed Vessels in the Marlborough Sounds," Marlborough District Council, Blenheim, 2000.

[58] Rails, "NZ Rail Plans Fast Ferry for Cook Strait This Summer," Rails, January 1994, pp. 28-29. 